ISSN: 2162-3104 Print/ ISSN: 2166-3750 Online

Volume 8, Issue 1 (2018), pp. 1-20

Journal of International Students

http://jistudents.org/

doi: 10.5281/zenodo.1101024

\title{
Away from Home: \\ A Qualitative Exploration of Health Experiences of Nigerian Students in a U.K. University
}

\author{
Folashade T. Alloh \\ Desiree Tait \\ Clare Taylor \\ Bournemouth University, United Kingdom
}

\begin{abstract}
This study explored the factors that contribute to the health experience of Nigerian students in the United Kingdom. Challenges faced by international students include dietary issues, isolation, stress, depression and others. Nine semi-structured interviews were conducted combination of purposive sampling and snowball sampling techniques were used to recruit participants for the study. Interviews were audio recorded, transcribed and analysed using thematic content analysis and Interpretative phenomenological analysis (IPA) to interpret themes. Two major themes from our findings were discussed under broad headings: Transitional changes and financial capability. These findings have practical implications for Nigerian students' well being in a U.K. university. Cultural dimension is needed to reduce culture shock experience among international students during sojourning.
\end{abstract}

Keywords: dietary issues, experience, health, Nigerian students

Studies have been conducted on the social and emotional effects of studying abroad on international students especially in United States (Cemalcilar \& Falbo, 2008; Jackson \& Heggins, 2003). Factors such as social exclusion, change in environment can lead to lifestyle changes, insufficient medical 
control and genetic factors are some of the factors responsible for health deterioration among migrants especially in black African migrants (Modesti et al., 2014). Although, these factors might not be the same among international students from Africa, Nigeria to be precise it is still important to explore them among these students. While it is appreciated that these factors might not be completely apply to Nigerian students in the United Kingdom, it is however, important to not neglect the possible effect they may have on health of international students (Cahill \& Stavrianeas, 2013).

There is rapid increase in the rate of mobility of international students studying in cultures and environment different from their own (Budde-Sung, 2011). Nigerian students are the third largest body of international students in the United Kingdom after China and India and are largest from Africa (Shaw \& Ratcliffe, 2014). Currently it is estimated that more than 16,000 students are registered as international students in the United Kingdom from Nigeria (Higher Education Statistics Agency 2017). This research is necessary to assist in understanding the different experiences of international students and how these experiences contribute to the health while studying. Another reason for conducting this research is to help in understanding the conditions that affect the health of international students during their study period abroad as settling in a new culture can affect health experience in different aspects (Landrine \& Klonoff, 2004). Nigerian students were interviewed for this study because of the high representation of these students in all U.K. universities. This study is important as it contributes to the understanding of health experiences of international students whose experiences has not been explored adequately especially among African students in U.K. universities.

Therefore, this study aims to explore the health experiences of Nigerian students and how studying abroad contribute to their health. In addition, Cetinkaya and colleagues noted the paucity of studies on wellbeing of international students (Cetinkaya-Yildiz, Cakir, \& Kondakci, 2011). As a result of the paucity of literature on the health experience of international students, we have conducted this study on Nigerian students. Furthermore, international students sojourning abroad have been reported to encounter difficulties that contribute to problems with adjustment to the new environment and presenting acculturative stress (Smith \& Khawaja, 2011; Zhou, Jindal-Snape, Topping, \& Todman, 2008). 


\section{LITERATURE REVIEW}

To set the scene for this study, a review of current relevant and literature was conducted. As a result of the growing number of international students studying abroad has attracted research. However, there are limited studies conducted on the wellbeing of these students and even fewer studies on international students from Africa. Studies reported that international students experienced several challenges during studies abroad. International students have difficulty socializing especially with local students, which can lead to depression (Graham, 2012). Alcohol was identified as a barrier to socializing due to the high consumption of alcohol among local population as compared their home countries.

Studies that have been conducted on international have focused on diet and role of acculturation. While some studies have reported changes in the diet of international students have been reported to include less healthy options (Amos \& Lordly, 2014; Cahill \& Stavrianeas, 2013; O'Sullivan \& Amirabdollahian, 2016; Santos, Vilela, Padrão, \& Caraher, 2015). However, a study reported international students cook their own and consumed less fast food as they see it as expensive and unhealthy (Yue, Lê, \& Terry, 2014). This might be due to the context in which the studies were conducted and also level of integration might contribute to the differences reported in diet of international students. Physical activity was reported to decrease among international students during study period abroad (Cahill \& Stavrianeas, 2013; Graham, 2012). However, it was reported that increased physical activities among Chinese international students as a need for them to fit into American society (Yan \& Cardinal, 2013). As earlier mentioned, the need for integration in to the society international students find themselves might have encouraged the increased physical activity level.

Isolation, loneliness, social exclusion, depression, acculturative stress, security challenges, and limited healthcare access are some of the challenges faced by international students (Blee, Reavley, Jorm, \& McCann, 2015; Brown \& Holloway, 2008a, 2008b; Gomes, Berry, Alzougool, \& Chang, 2014; Lê, Auckland, Nguyen, \& Terry, 2013; Schartner, 2015; Yue $\&$ Lê, 2012). There is limited psychological intervention to help reduce the stress faced by international students studying abroad (Smith \& Khawaja, 2011). Loneliness experienced by international students can only be addressed by creating environment for interaction with the new culture and allowing them to rewrite their own cultural map (Sawir, Marginson, Deumert, Nyland, \& Ramia, 2008). This means there is need to explore cultural influence on health behaviour of international students especially 
among African students. Also, health care access is limited due to discrimination and restricted health coverage (Poljski, Quiazon, \& Tran, 2014).

Sawir et al. (2008) argued that major part of literature focus on academic experiences of international students while only fewer research focuses on lives and experiences of these students. These experiences influences health and invariably affect their academic performance. As a result of these findings in studies among international students suggested that it is essential to explore experiences of international students' especially Nigerian students. There is a paucity of studies on Nigerian students especially on how lived experiences contribute to health of the students. In addition to the challenges discussed as facing international students during study abroad, Nigerian students come from a collectivist culture that is different from the western individualistic culture (Triandis, 2001). The resources and stress required to adapt to their new environment can affect their health and wellbeing. (Brown \& Holloway, 2008b) argued that given the economical dependency of universities on international students' fees, it is important to understand the fully the challenges facing these students during sojourning so that these can be addressed to allow optimum service delivery to these students. This is why it is essential that this study is conducted to explore the health experiences of these students and how these experiences has changed form when they were back in Nigeria.

There are implications that suggest international students experience culture shock as a result of the cultural differences experienced during sojourning. Therefore, culture shock theoretical framework was adopted to explain the health experience of international students in a U.K. university. However, there are several approaches to culture shock as explained by (Zhou, Jindal-Snape, Topping, \& Todman, 2008). The negative life-events culture shock approach was adopted from the several culture shock approaches. This theory was adopted as explained, the theory explained that migration involves life changes and adaption to change is stressful. This theory implies that there are changes that are experienced by international students as a result of the cultural changes experienced on their sojourner journey that can be stressful. This in effect can affect the health experience of these students during their study. Therefore, this study is designed to explore those changes that Nigerian students precisely experience as a result of cultural and environmental changes due to sojourning. Also, how these experiences contribute to their health while sojourning. 


\section{RESEARCH METHOD}

A qualitative research paradigm was used as the method of collecting and analysing data due to the research question for this study. Qualitative methodology draws on the fact that realities are socially dependent, modified and shaped by history, social, cultural practices and political processes that take place around individuals (Green \& Thorogood, 2013). Therefore, a qualitative approach was used to conduct the study as it will draw from experiences of participants and their meaning of these experiences. Eligible participants that were recruited for the study are all Nigerians that migrate to the United Kingdom for postgraduate studies. However, adults were the focus of the study and so participants within the young adult's age group of 20-40 years were recruited (Jenks, 2005). Purposive sampling method was used to recruit participant (Koerber \& McMichael, 2008). Due to the difficulty in recruiting students that were busy with academic work, snowball sampling was also employed by getting contacts of possible participants that met the inclusion criteria from already willing participants. Three of the contacted participants were recruited and interviewed using snowball sampling technique.

Participants were recruited through student groups in and around southeast of England. Participants' recruitment started in May 2015 with the placement of advert social media pages. Using purposive sampling method, two participants were recruited and interviewed for the pilot study, which was included in the result analysis as nothing was changed in the interview guide. Although the study was not on sensitive topic, it still was difficult to get participants mainly due to the busy schedules of most students as they were working on their dissertation at the time of conducting the study. Alternatively, video call over the Internet was suggested as a medium to conduct the interview. However, face-to-face interview is better as facial expressions and body movements can be easily read, all of which contributes to the notes taking during the interview.

The inclusion criteria were used to recruit participants that have deeply rooted linkage to Nigeria and have experiences of being a student and living in the United Kingdom. Face to face in-depth interviews guided by a semi-structured interview guide were conducted. All participants recruited were able to communicate in English due to their level of education; therefore, all interviews were conducted in English. This also removed the need to exclude some individuals on language barrier basis or the need to get a translator. The questions included in the interview guide were based on the findings of the literature review completed prior to the 
study. After the ninth participant was interviewed, data saturation was reached and interview stage of the research was concluded. The interview ranged from shortest time of 21 min to longest time of 49 min with an average time of $33 \mathrm{~min}$.

Audio records of interview were transcribed and analysed with all other notes taken during the interview (Ritchie, Lewis, Nicholls, \& Ormston, 2013). Data analysis began as soon as the interviews were transcribed to ensure that researchers remained immersed in the data. Data analysis was done manually; this is to allow familiarity of researchers with the transcripts and participants stories. The data generated from the transcripts were analysed using thematic content analysis (Keenan, van Teijlingen, \& Pitchforth, 2015). All transcripts were read several times over to immerse the researcher in the data collected and to get a full sense of what each participant was describing (Klopper, 2008). Key points were noted during the analysis and then categorised to develop major themes and sub-themes (Klopper, 2008). An interpretive phenomenological approach (IPA) was used to interpret themes generated. (Shinebourne \& Smith, 2009) explained that the aim of IPA is to illustrate, inform and masters themes by firmly attaching findings from direct quotes from participants account. Participant's quotes and reports were used to develop themes that constitute the findings in this study. The combination of these methods of data analysis is considered appropriate for the study, because thematic content analysis identify themes and reports the pattern within a set of data (Braun \& Clarke, 2006). Thematic analysis also fits with the steps involved in interpretative phenomenology approach (Smith, 2011). Key points were noted during the analysis and then categorised to develop major themes and sub themes (Klopper, 2008). A coding frame was developed to reflect all emerging themes illustrated with verbatim quotation. Thematic coding of all transcripts was conducted using the coding frame.

Ethical approval was granted by the research ethics committee of Bournemouth University and pseudonym was used to protect participant's privacy while still giving readers the feel of familiarity with the participants in the study (Dearnley, 2005; Guenther, 2009). No form of coercion or incentives was used to recruit participants as they all participated voluntarily (Buchanan \& Hvizdak, 2009).

All participants are Nigerian students studying at the master's-level in a U.K. university (see Table 1). 
Table 1. Participants' profile information.

\begin{tabular}{lccccc}
\hline Name & Age & Sex & $\begin{array}{r}\text { Length of stay in } \\
\text { the UK (Months) }\end{array}$ & Degree & $\begin{array}{c}\text { Part-time } \\
\text { job }\end{array}$ \\
\hline Ben & 31 & Male & 9 & Master's & Yes \\
Gbenga & 25 & Male & 10 & Master's & Yes \\
Chike & 28 & Male & 10 & Master's & Yes \\
John & 33 & Male & 6 & Master's & No \\
Tope & 35 & Female & 10 & Master's & Yes \\
Mary & 24 & Female & 10 & Master's & Yes \\
Ogene & 22 & Female & 10 & Master's & No \\
Ngozi & 26 & Female & 10 & Master's & Yes \\
Joy & 25 & Female & 10.5 & Master's & Yes \\
\hline
\end{tabular}

Note. All names are pseudonyms to ensure participant's confidentiality.

\section{RESULTS}

The major themes identified in this study are transitional changes, healthcare services and financial capability. All these are explained in detail with subthemes identified.

\section{Theme: Transitional Changes}

The lived experiences of most of the participants were influenced by acculturation. Most participants that identified acculturation as a factor in their experiences related it to the type of diet they eat since coming to the United Kingdom. This took the form of change in diet, weight changes, physical activity, stress and or depression, alcohol and smoking.

\section{Change in Diet}

Some acknowledged changes in diet especially in the aspect of incorporating British meals to their diet plan. For example: “. . . I eat English breakfast, like bacon, egg and the likes ..." - Chike, 28

From the participant's accounts, it was noted that many of them still identified with their traditional foods although they have adopted British meals as well. For example: “. . . Another day I might decide to eat British food I may eat sandwich or pancake. . ." - Gbenga, 25 
Many of the participants interviewed reported changes in diet, mainly foods with high fatty content, dense calories, refined and processed meals and sugary meals. Some participants are of the opinion that these kinds of diet impacts negatively on their health. For example:

". . . but here because of the availability of readymade food called junks. So, I just eat a lot of stuff that is already pre-packaged. I think my diet is negatively impacting my health, the diet is just too bad (Laughing)." -Mary, 24

\section{Change in Weight}

Changes in diet due to acculturation seem to lead to change in weight, most of the participants reported noticeable increase in weight since moving to the United Kingdom. Many placed emphasis on the amount of weight gained within the short period of their stay in the United Kingdom as compared to Nigeria. They were concerned about their weight gain. This is unlike the general assumption that Africans associate weight gain with good health, this might be the effect of environmental change as they are more aware of their health. For example:

“. . I have gone fatter, well like I said I grew fatter so obviously it's not better. . " -Ogene, 22

“. . I have gained weight. . ."-Mary, 24

Transitional changes affect physical activities experiences of participants, some participants reported low level of physical activities mainly due to the sedentary lifestyle promoted by studying. For instance: "So there is less physical activity as I used to do back home, back home I can walk long distances but here I mostly stay and work in my room." -John, 33

Another participant reported walking as the only means to be physically active. "That is it basically because so far, as I have been here I have not involved in any exercise physical apart from the walking. That's all." -Ben, 31

There was report of weight gain even with access to the available physical activity facility by some participants. Especially among those that access these facilities, unlike in Nigeria where there is limited access to these facilities. For example:

"Here which is very ironic because here you have the things that you may need to maintain good weight loss, for example, you have a 
long stretch of beach where you can run, you have exercise gear, gym membership that you can easily get access to but somehow I have managed to not utilize it." -Ngozi, 26

\section{Stress/Depression}

A good number of participants reported that stress is a major factor in their living experiences in the United Kingdom. The combination of meeting academics and making the transition to a new environment amplify the level of stress they experienced. The stress experienced by some participants led to depression, this might be due to adapting to a new environment, leaving home. As explained by the culture shock theory that predicts stress as a result of adjustment to unfamiliar culture. For example: “. . Initially, when I first came I will say that I was having a depressing time. . ."-Mary, 24

Ngozi explained how she is still experiencing stress as a result of school demands and how it is affecting her food consumption. "Like I worried a lot even with school and stuffs like that . . Am stressing out so much and I just wanted to just drown myself in food." -Ngozi, 26

However, a different experience was reported by Gbenga that the stress level is minimal as compared to what is experienced in Nigeria and so a lot less stressful. For example: "It's not stressful. . . Living experience is not stressful here." - Gbenga, 25

Ogene reported that they experienced some effect dues to level of stress they experience. For example:

"Okay like me I had hormonal change and my period started messing around. . . I don't know if it's the weather or stress but I think that I what most will go through especially females. . I don't sleep well, now I have insomnia." -Ogene, 22

In general, female participants seem to experience more stress and show manifestation in physical health than male participants. This might be an indication for more support needed by female students during sojourning.

\section{Alcohol and Smoking}

A sub-theme that influenced the transition of participants is the United Kingdom is the level of smoking and alcohol; all participants interviewed do not smoke and have never smoked. 
Joy had facial expressions that questioned why ask if she smokes or drinks alcohol. This is might be the irresponsible behaviour attached to smoking in her home country and society should not condone such habit. For example: "No, I don't do both. .."-Joy, 25

While some of the participants were indifferent about others smoking, others were so worried about their health due to the high rate of smokers in the United Kingdom as compared to Nigeria. Tope and John were very concerned about their health as they fear becoming passive smokers themselves. For example: "The environment is okay but I don't like what people do with their environment as everybody is a smoker virtually. . . I thought I will become a passive smoker. "-John, 33

Four participants take alcohol; however, they reported high reduction in the level of alcohol intake since coming to the United Kingdom. They pointed to alcohol as the major reason for the decrease intake and the limited time to socialise. For instance: "No I don't smoke, but sometimes I just take maybe some wine alcoholic wine. . No, no it has reduced as I have no time for that, I have no time." -Ben, 31

Transition was strongly represented in all participants' account of living experience in the United Kingdom. While some positive effect of transition on health was noted, most are worried about the negative impact of transition as they try to find their way around a new environment.

\section{Theme: Financial Capability}

All the participants interviewed reported how socioeconomic factor has influenced their health and living experience while studying. Many stated that living in the United Kingdom is very expensive and so contribute to their health experience.

\section{Financial Barrier to Healthy Diet}

Inadequate financial capability affects different aspects of living, Ngozi reported finance affects the type of food she eats and when she gets to eat it. For example, Ngozi and Mary said it is very expensive to eat healthily and will go for cheap junk meal since that is what they can afford. For instance: "You will think that you will be getting a lot of healthy things for a reasonable cheap price but it's not always like that and also when you don't have time to cook." -Ngozi, 26 
As Mary mentioned, environment plays major role in promoting healthy eating, since the environment she finds herself encourage junk meals as they are cheaper than healthy meals unlike what she was used to at home.

". . . but the truth of the matter is it is so much more expensive and stressful to eat healthy in this country.... because back home healthy meals like fruits and vegetables are cheaper and you will find them even on the sides of the road, so much cheaper than buying biscuit." -Mary, 24

\section{Health Dependency on Finance}

Joy pointed that for any effort to effectively improve the health experience of student's especially international student, it will have to depend on the financial capability of the students. For example:

"Anything I can say is the money because if you want to register for a gym you have to pay, then if you want to eat good food you have to have enough money to get them and treatment too you have to have enough money before you can buy any treatment. So, improving living experience depends on money from my view." Joy, 25

All participants reported a negative effect of finance on health experience in the United Kingdom as they all agreed living in the United Kingdom is very expensive and even more expensive to adopt and maintain healthy behaviour and lifestyle.

\section{Rigor}

Winson argued that irrespective of the methodology employed in a primary research; both qualitative and quantitative methodology requires maximized efficiency and validity (Winter, 2000).

All interviews were carefully transcribed to include every word, hesitation, laughs, pause and true to the audio recordings. Conformability was evidence in the clear and thorough procedures followed in regard to how participants were recruited, interviews conducted and how the data coding and analysis were conducted. AF conducted all interviews, audio transcription and initial coding of the transcripts. To ensure transparency, $\mathrm{CT}$ and DT examined transcripts and initial coding while all authors (AF, CT, DT) conducted the final coding and analysis of themes. 
Transcripts and data previously coded were revisited periodically to ensure stability over time (Shenton, 2004). Transferability of this study was achieved by providing readers with thick description of the study setting and context such as demographic information of participants (Table 1) to allow readers to be able to decide if this study is transferable to their own specific setting and context (Lewis \& Ritchie, 2003; Ritchie et al., 2013; Shenton, 2004).

\section{DISCUSSION}

This study was conducted to explore the health experiences of Nigerian students in a U.K. university. This was done because of the transitional challenges that are faced by international students from the literature. The purpose of this study was to understand the effect of culture shock on the health experience of Nigerian students studying in a U.K. university. Having moved from their country to a with collectivist culture to an individualistic culture of United Kingdom poses culture shock experiences that can be stressful and have effect on health experience of these students.

International students experience changes in lifestyle when they arrive in the host country. This study found that many students experience changes in lifestyle. Diet was a vital change that was reported as most participants identified changes in diet. Low consumption of vegetables, fruits, protein, and fish while increased intake of fatty, dense calorie foods like snacks, soft drinks were also reported. Studies reported similar findings among international students that they consume fewer fruits and vegetables daily (Amos \& Lordly, 2014; Papadakos, Hondros, Scott, \& Kapsokefalou, 2007). Some factors suggested explaining diet changes among international students include inadequate information on healthy meal options, price, food availability and convenience of junk food.

Furthermore, because traditional foods are relatively scares due to limited importation, there are also very expensive and limited choices are reasons suggested for meal choices among young migrants including international students (Gilbert \& Khokhar, 2008). Generally, there is reduced level of physical activity and exercise among participants, especially when compared to physical activities level in country of birth (Nigeria).

As a result of the dietary and physical activity changes reported by participants in this study, most participants also reported weight gain. Similar findings were reported among international students in United States as they reported increase in weight and reduced level of physical activity 
(Cahill \& Stavrianeas, 2013). High saturated fat and high sodium consumptions, in addition to low physical activity, can lead to weight gain and eventually obesity. Obesity is an independent risk factor for cardiovascular diseases (Engeland, Bjørge, Tverdal, \& Søgaard, 2004; Ferrara, 2009; Nelson, Story, Larson, Neumark-Sztainer, \& Lytle, 2008). In addition, these diseases are increasingly prevalent among young adults (where most university students fall in age classification) unlike previously when they were known as older adult's diseases (Bibbins-Domingo, Coxson, Pletcher, Lightwood, \& Goldman, 2007).

Alcohol emerged as a factor in the lived experiences of participants in this study. Most participants reported no consumption of alcohol. Few participants that do consume alcohol, however, reported a reduction in the level of alcohol intake since coming to the United Kingdom, mainly due to the expense of paying for alcohol. This is unlike the findings from studies in the United States, where there is an increase in the consumption of alcohol by international students (Cahill \& Stavrianeas, 2013). This might be as a result of the cultural differences making integration and socialisation difficult for international students. In addition, the low financial capability of the few participants that consume alcohol might partly explain the reduce alcohol consumption reported.

Other sub-themes that affect transition experience of Nigerian students include family support, limited time outside school demands are some of the other factors that participants pointed to as many stated that stress and lack of family societal support make them feel isolated and depressed.

The collectivist culture practiced in Nigeria makes this more pronounced as they are missing the family and societal support they are used to having while in Nigerian communities unlike the individualistic culture practiced in the United Kingdom. Financial capability was another important factor that influences the health experience of Nigerian students in this study. Most participants highlighted the high cost of living in the United Kingdom when compared to Nigeria as a barrier to adopting healthy behaviours. Many indicated that diet, physical activities and more all depend on their financial capability and will likely experience better health if finance was affordable for them. (Cahill \& Stavrianeas, 2013) reported financial capability as a barrier to accessing healthy diet, gym membership among international students in the United States.

Diet was mostly affected by finance as most reported that fruits and vegetables are expensive as compared to their home country and so will rather go for cheaper less healthy options. Socioeconomic factors were also 
identified as barriers to the uptake of health care services. In general, the health of students was negatively affected. However, on the other hand, there are healthy changes in the lifestyle of students in this study. For example, the level of alcohol intake reduced among the few participants that reported alcohol consumption due to the inadequate financial capability to afford alcohol.

This study has several strengths, as noted from literature, Nigerian students' health experiences have not been explored in the United Kingdom. This study gives voice to this group of student that have left their home country to study in the United Kingdom. In addition, using qualitative methodology in this study allowed for thick description of participants experiences and better understanding of this vulnerable group of students without family support. Limitations in this study include a small sample size and self-reporting bias. Larger sample size would have given a broader representation of the research group in this study. However, the sample size was justified as the aim of phenomenology studies like this one is not generalisation but to offer in-depth understanding of the phenomenon of study. There is a potential for self-reporting bias as participants might only report what they think is socially acceptable.

\section{CONCLUSION}

Nigerian students in U.K. universities are faced with several challenges that impact on their health. Unhealthy diet consumption, low level of physical activity, stress, and inadequate finance are some of the many factors that contribute to the health experience of these students. These are mainly due to inadequate and poor nutritional understanding of the host country's diet, cost, availability and convenience. More effort is needed to understand and help maintain good health among this group of students because of the importance of international students both financially and diversity wise in U.K. universities.

\section{IMPLICATIONS}

This research has shown that Nigerian students face challenges during their sojourning. These challenges contribute to their daily life while studying which in effect influence their health during this period. It in effect shows that higher institution of learning needs to look further than academic welfare of the students. 
Currently, universities in the United Kingdom offer orientation programme for international students on arrival to the school (Brown \& Holloway, 2008b). They also offer pre-arrival information websites and magazines for new intakes to access. However, information is usually focused on academic support materials and accommodation options. From the findings of this study, it is recommended that Universities look beyond academic support to include health and wellbeing supports especially tailored support for international students. In addition, these orientations are usually last for one week at the start of the academic year. Universities need to repeat these events to after resumption week as some students resume after the resumption week due to visa processing issues that leaves them without adequate support for studying. Finally, these orientation events need to adopt cultural approach for international students. This is because of the differences in culture of these students and the new environment. Transition factors like diet, physical activity and financial capabilities of international students needs to be considered in health promotional services provided by universities. In the area of transition of Nigerian and African students in general to the United Kingdom, Universities can create healthy dietary information booklets with familiar recipes and ingredients and where to access them around the University community. This is because an issue is the unfamiliar English meals that are represented on the "Healthy Food plate" which might make them settle for readymade junk meals as they are not familiar with the healthy meal options and their preparation in the food plate.

Importantly dietary information is needed to help them make informed dietary decisions and healthy diet should be encouraged through health promotional services that are tailored specifically for this group of students with special dietary needs (Cahill \& Stavrianeas, 2013; Moreno et al., 2008). Also, because studies have suggested that weight gain is associated with low level of physical activities, health promotional services can be introduced to encourage physical activities (Boyle \& LaRose, 2009; Ferrara, 2009; Gómez-López, Granero-Gallegos, \& Baena-Extremera, 2011) There is a need for more information and orientation of this group of students to healthy dietary options in the United Kingdom. Managing weight gain and healthy eating options could be supported through sports programmes, reduced gym membership fee for students and dietary orientation or other avenues. Most international students pay tuition fees through family resources, thereby putting pressure on the students to excel academically while facing transitional challenges to settle in a new environment. More effort is needed in terms of preparation to settle this 
group of international students in the United Kingdom. So, they can achieve better academic performance and better general health wellbeing in the process.

\section{REFERENCES}

Amos, S., \& Lordly, D. (2014). Picture this: A photovoice study of international students' food experience in Canada. Canadian Journal of Dietetic Practice and Research, 75(2), 59-63. doi: 10.3148/75.2.2014.59

Bibbins-Domingo, K., Coxson, P., Pletcher, M. J., Lightwood, J., \& Goldman, L. (2007). Adolescent overweight and future adult coronary heart disease. New England Journal of Medicine, 357(23), 2371-2379. doi: 10.1056/NEJMoa0907355

Blee, F. L., Reavley, N. J., Jorm, A. F., \& McCann, T. V. (2015). Student driven mental health promotion in an Australian university setting. Mental Health \& Prevention, 3(1), 26-33. doi: 10.1016/j.mhp.2015.04.004

Boyle, J. R., \& LaRose, N. R. (2009). Personal beliefs, the environment and college students' exercise and eating behaviors. American Journal of Health Studies, 23(4), 195-200.

Braun, V., \& Clarke, V. (2006). Using thematic analysis in psychology. Qualitative Research in Psychology, 3(2), 77-101. doi: 10.1191/1478088706qp063oa

Brown, L., \& Holloway, I. (2008a). The adjustment journey of international postgraduate students at an English university An ethnographic study. Journal of Research in International Education, 7(2), 232-249. doi: $10.1177 / 1475240908091306$

Brown, L., \& Holloway, I. (2008b). The initial stage of the international sojourn: excitement or culture shock? British Journal of Guidance \& Counselling, 36(1), 33-49. doi: 10.1080/03069880701715689

Buchanan, E. A., \& Hvizdak, E. E. (2009). Online survey tools: Ethical and methodological concerns of human research ethics committees. Journal of Empirical Research on Human Research Ethics, 4(2), 37-48. doi: 10.1525/jer.2009.4.2.37

Budde-Sung, A. E. (2011). The increasing internationalization of the international business classroom: Cultural and generational considerations. Business Horizons, 54(4), 365-373. doi:10.1016/j.bushor.2011.03.003

Cahill, C. R., \& Stavrianeas, S. (2013). Assessing dietary changes in international students and the barriers to healthy living abroad: A review. Journal of Exercise Physiology Online, 16(4), 51-64.

Cemalcilar, Z., \& Falbo, T. (2008). A longitudinal study of the adaptation of international students in the United States. Journal of Cross-Cultural Psychology, 39(6), 799-804. doi: 10.1177/0022022108323787

Cetinkaya-Yildiz, E., Cakir, S. G., \& Kondakci, Y. (2011). Psychological distress among international students in Turkey. International Journal of Intercultural Relations, 35(5), 534-539. doi: 10.1016/j.ijintrel.2011.04.001 
Dearnley, C. (2005). A reflection on the use of semi-structured interviews. Nurse Researcher, 13(1), 19-28. doi: 10.7748/nr2005.07.13.1.19.c5997

Engeland, A., Bjørge, T., Tverdal, A., \& Søgaard, A. J. (2004). Obesity in adolescence and adulthood and the risk of adult mortality. Epidemiology, 15(1), 79-85. doi: 10.1097/01.ede.0000100148.40711.59

Ferrara, C. M. (2009). The college experience: Physical activity, nutrition, and implications for intervention and future research. Journal of Exercise Physiology, 12(1), 23-35.

Gilbert, P. A., \& Khokhar, S. (2008). Changing dietary habits of ethnic groups in Europe and implications for health. Nutrition Reviews, 66(4), 203-215. doi: 10.1111/j.1753-4887.2008.00025.x

Gomes, C., Berry, M., Alzougool, B., \& Chang, S. (2014). Home away from home: International students and their identity-based social networks in Australia. Journal of International Students, 4(1), 2-15.

Gómez-López, M., Granero-Gallegos, A., \& Baena-Extremera, A. (2011). The abandonment of an active lifestyle within university students: Reasons for abandonment and expectations of re-engagement. Psychologica Belgica, 51(2). doi: $10.5334 / \mathrm{pb}-51-2-155$

Graham, L. (2012). "Socialising through exercise perhaps is a gift from heaven": The relevance of a sport and recreation service to the needs of international students. International Journal of Sport \& Society, 3(2), 191-200.

Green, J., \& Thorogood, N. (2013). Qualitative methods for health research. Thousand Oaks, CA: Sage.

Guenther, K. M. (2009). The politics of names: Rethinking the methodological and ethical significance of naming people, organizations, and places. Qualitative Research, 9(4), 411-421. doi: 10.1177/1468794109337872

Higher Education Statistics Agency. (n.d.). Higher education student enrolments and qualifications obtained at higher education providers in the United Kingdom 2015/16. Higher Education Statistics Agency. Retrieved from https://www.hesa.ac.uk/news/12-01-2017/sfr242-student-enrolments-andqualifications.

Jackson, J. F., \& Heggins, W., III. (2003). Understanding the collegiate experience for Asian international students at a Midwestern research university. College Student Journal, 37(3), 379-391.

Jenks, C. (2005). Childhood (2nd ed.). London: Routledge.

Keenan, K. F., van Teijlingen, E., \& Pitchforth, E. (2015). The analysis of qualitative research data in family planning and reproductive health care. Journal of Family Planning and Reproductive Health Care, 31(1), 40-43. doi: $10.1783 / 0000000052972825$

Klopper, H. (2008). The qualitative research proposal. Curationis, 31(4), 62-72.

Koerber, A., \& McMichael, L. (2008). Qualitative sampling methods a primer for technical communicators. Journal of Business and Technical Communication, 22(4), 454-473. doi: 10.1177/1050651908320362 
Landrine, H., \& Klonoff, E. A. (2004). Culture change and ethnic-minority health behavior: An operant theory of acculturation. Journal of Behavioral Medicine, 27(6), 527-555. doi: 10.1007/s10865-004-0002-0

Lê, Q., Auckland, S., Nguyen, H. B., \& Terry, D. R. (2013). The safety of international students in a regional area of Australia: Perceptions and experiences. Journal of the Australia and New Zealand Student Services Association, 42, 15-24.

Modesti, P. A., Bianchi, S., Borghi, C., Cameli, M., Capasso, G., Ceriello, A., \& Muiesan, M. L. (2014). Cardiovascular health in migrants: current status and issues for prevention. A collaborative multidisciplinary task force report. Journal of Cardiovascular Medicine, 15(9), 683-692. doi: 10.2459/ JCM.0000000000000069

Moreno, L., Gonzalez-Gross, M., Kersting, M., Molnar, D., De Henauw, S., Beghin, L., . . . Gilbert, C. (2008). Assessing, understanding and modifying nutritional status, eating habits and physical activity in European adolescents: the HELENA (Healthy Lifestyle in Europe by Nutrition in Adolescence) Study. Public Health Nutrition, 11(3), 288-299. doi: 10.1017/ S1368980007000535

Nelson, M. C., Story, M., Larson, N. I., Neumark- Sztainer, D., \& Lytle, L. A. (2008). Emerging adulthood and college- aged youth: An overlooked age for weight- related behavior change. Obesity, 16(10), 2205-2211. doi: 10.1038/oby.2008.365

O'Sullivan, N., \& Amirabdollahian, F. (2016). Loyal tongue, liberal mind: International students' experiences on dietary acculturation in England. Journal of International Students, 6(1), 107-127.

Papadaki, A., Hondros, G., Scott, J. A., \& Kapsokefalou, M. (2007). Eating habits of university students living at, or away from home in Greece. Appetite, 49(1), 169-176. doi:10.1016/j.appet.2007.01.008

Poljski, C., Quiazon, R., \& Tran, C. (2014). Ensuring rights: Improving access to sexual and reproductive health services for female international students in Australia. Journal of International Students, 4(2), 150-163.

Ritchie, J., Lewis, J., Nicholls, C. M., \& Ormston, R. (Eds.). (2013). Qualitative research practice: A guide for social science students and researchers. Thousand Oaks, CA: Sage.

Santos, S., Vilela, S., Padrão, P., \& Caraher, M. (2015). Sex- related dietary changes of Portuguese university students after migration to London, UK. Nutrition \& Dietetics, 72(4), 340-346. doi: 10.1111/1747-0080.12154

Sawir, E., Marginson, S., Deumert, A., Nyland, C., \& Ramia, G. (2008). Loneliness and international students: An Australian study. Journal of studies in international education, 12(2), 148-180. doi: 10.1177/1028315307299699

Schartner, A. (2015). 'You cannot talk with all of the strangers in a pub': A longitudinal case study of international postgraduate students' social ties at a British university. Higher Education, 69(2), 225-241. doi:10.1007/s10734014-9771-8 
Shaw, C., \& Ratcliffe, R. (2014). Nigerian postgrads set to outnumber Indian students in UK universities. The Guardian. Retrieved from https://www.theguardian.com/education/2014/oct/07/-sp-nigerian-postgradsset-to-outnumber-indian-students-in-uk-universities.

Shenton, A. K. (2004). Strategies for ensuring trustworthiness in qualitative research projects. Education for information, 22(2), 63-75. doi: 10.3233/EFI2004-22201

Shinebourne, P., \& Smith, J. A. (2009). Alcohol and the self: An interpretative phenomenological analysis of the experience of addiction and its impact on the sense of self and identity. Addiction Research \& Theory, 17(2), 152-167. doi: $10.1080 / 16066350802245650$

Smith, J. A. (2011). Evaluating the contribution of interpretative phenomenological analysis. Health psychology review, 5(1), 9-27. doi: 10.1080/17437199.2010. 510659

Smith, R., \& Khawaja, N. (2011). A review of the acculturation experiences of international students. International Journal of Intercultural Relations, 35(6), 699-713. doi: 10.1016/j.ijintrel.2011.08.004

Triandis, H. C. (2001). Individualism and collectivism: Past, present, and future. In D. Matsumoto (Ed.), The handbook of culture and psychology (pp. 35-50). Oxford: Oxford University Press.

Winter, G. (2000). A comparative discussion of the notion of'validity'in qualitative and quantitative research. The Qualitative Report, 4(3), 1-14.

Yan, Z., \& Cardinal, B. J. (2013). Perception of physical activity participation of Chinese female graduate students: A case study. Research quarterly for exercise and sport, 84(3), 384-396. doi:10.1080/02701367.2013.813895

Yue, Y., \& Lê, Q. (2012). International students' social engagement and social wellbeing in an Australian regional area. International Journal of Health, Wellness \& Society, 2(3), 119-132.

Yue, Y., Lê, Q., \& Terry, D. R. (2014). Transition to an unfamiliar environment: International students' living experiences in an Australian regional area. Journal of the Australia and New Zealand Student Services Association, 43, $10-20$.

Zhou, Y., Jindal-Snape, D., Topping, K., \& Todman, J. (2008). Theoretical models of culture shock and adaptation in international students in higher education. Studies in Higher Education, 33(1), 63-75. doi: 10.3148/75.2.2014.59

FOLASHADE ALLOH, BSc, MSc, PhD Candidate, is a postgraduate researcher at Faculty of Health and Social Sciences at Bournemouth University.

DESIREE TAIT, RGN, DN, DNEd, MSc Nursing, DNSc, SFHEA, is a Senior Lecturer in Adult Nursing at faculty of Health and Social Sciences, Bournemouth University. Email: dtait@bournemouth.ac.uk 
CLARE TAYLOR, DipCOT, BA(Hons), PGCert, MA(Distinc), PhD, FHEA is a Senior Lecturer of occupational therapy at the faculty of Health and Social Sciences, Bournemouth University. Email: claret@ bournemouth.ac.uk

\section{ACKNOWLEDGMENT}

The authors will like to acknowledge the contribution of Dr. Pramod Regmi for the constructive feedback given throughout the write up process of this paper. 